\title{
Experimental study on size matching in a canine living- donor lobar lung transplant model
}

\author{
Takashi Fujita, MD \\ Hiroshi Date, MD \\ Kouji Ueda, MD \\ Itaru Nagahiro, MD \\ Motoi Aoe, MD \\ Akio Andou, MD \\ Nobuyoshi Shimizu, MD
}

From the Department of Surgery II, Okayama University School of Medicine, Okayama, Japan.

Received for publication Jan 9, 2001; revisions requested March 19, 2001; revisions received April 4, 2001; accepted for publication May 14, 2001.

Address for reprints: Hiroshi Date, MD, Department of Surgery II, Okayama University School of Medicine, 2-5-1 Shikata Cho, Okayama 700-8558, Japan (E-mail: hdate@ nigeka2.hospital.okayama-u.ac.jp).

J Thorac Cardiovasc Surg 2002;123:104-9

Copyright () 2002 by The American Association for Thoracic Surgery

$0022-5223 / 2002 \$ 35.00+0 \quad \mathbf{1 2 / 1 / 1 1 7 2 8 0}$

doi: $10.1067 / \mathrm{mtc} .2002 .117280$
Objective: In an effort to address the donor-shortage issue, living-donor lobar lung transplants have been performed with satisfactory results. The use of small grafts is potentially problematic because it could cause high pulmonary artery pressure, resulting in lung edema. The purpose of this study was to evaluate the effect of small grafts on early pulmonary function and to identify the predictor for acceptable size discrepancy.

Methods: Seventeen pairs of mongrel dogs with various donor-recipient sizes were used. Body weight, height, chest circumference, and lung weight were measured as size parameters. Right middle, lower, and cardiac lobes were implanted as a right lung of the recipient and the left lower lobe was implanted as a left lung without use of cardiopulmonary bypass. Pulmonary function of the recipient was measured for 6 hours after reperfusion.

Results: A significant negative correlation was found between donor/recipient body-weight ratio and mean pulmonary artery pressure at 1 hour $(r=-0.594, P=$ .025). A significant correlation was found between donor/recipient body-weight ratio and $\mathrm{PaO}_{2}$ at 6 hours $(r=0.704 ; P=.007)$. There was no significant correlation between the other 3 size parameters and postoperative pulmonary function. All 8 recipients with a donor/recipient body-weight ratio of 1.2 or greater survived the 6hour assessment period, and their $\mathrm{PaO}_{2}$ exceeded $500 \mathrm{~mm} \mathrm{Hg}$ at 6 hours.

Conclusions: Donor/recipient weight ratio is an important predictor of early pulmonary function in a canine living-donor lobar lung transplant model.

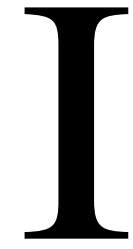

$\mathrm{n}$ recent years, lung transplantation has become an accepted treatment option for end-stage lung parenchymal and pulmonary vascular disease. However, the shortage of donor organs limits the use of this procedure. Approximately $20 \%$ of patients on recipient lists will die of their underlying pulmonary disease while awaiting identification of a suitable donor. ${ }^{1}$ The small-size population, including children, is further restricted because organ availability is limited by size discrepancies between the potential recipient and donor. Living-donor lobar lung transplantation may be indicated in properly selected patients. ${ }^{2,3}$ In living-donor lobar lung transplantation, only 2 lobes (usually lower lobes) are implanted. The use of significantly undersized grafts is potentially problematic because it could cause high pulmonary artery pressure, resulting in lung edema.

The purpose of this study was to evaluate the effect of small grafts on early pulmonary function in a newly developed canine bilateral living-donor lobar lung transplant model and to identify the predictor for acceptable size discrepancy. 

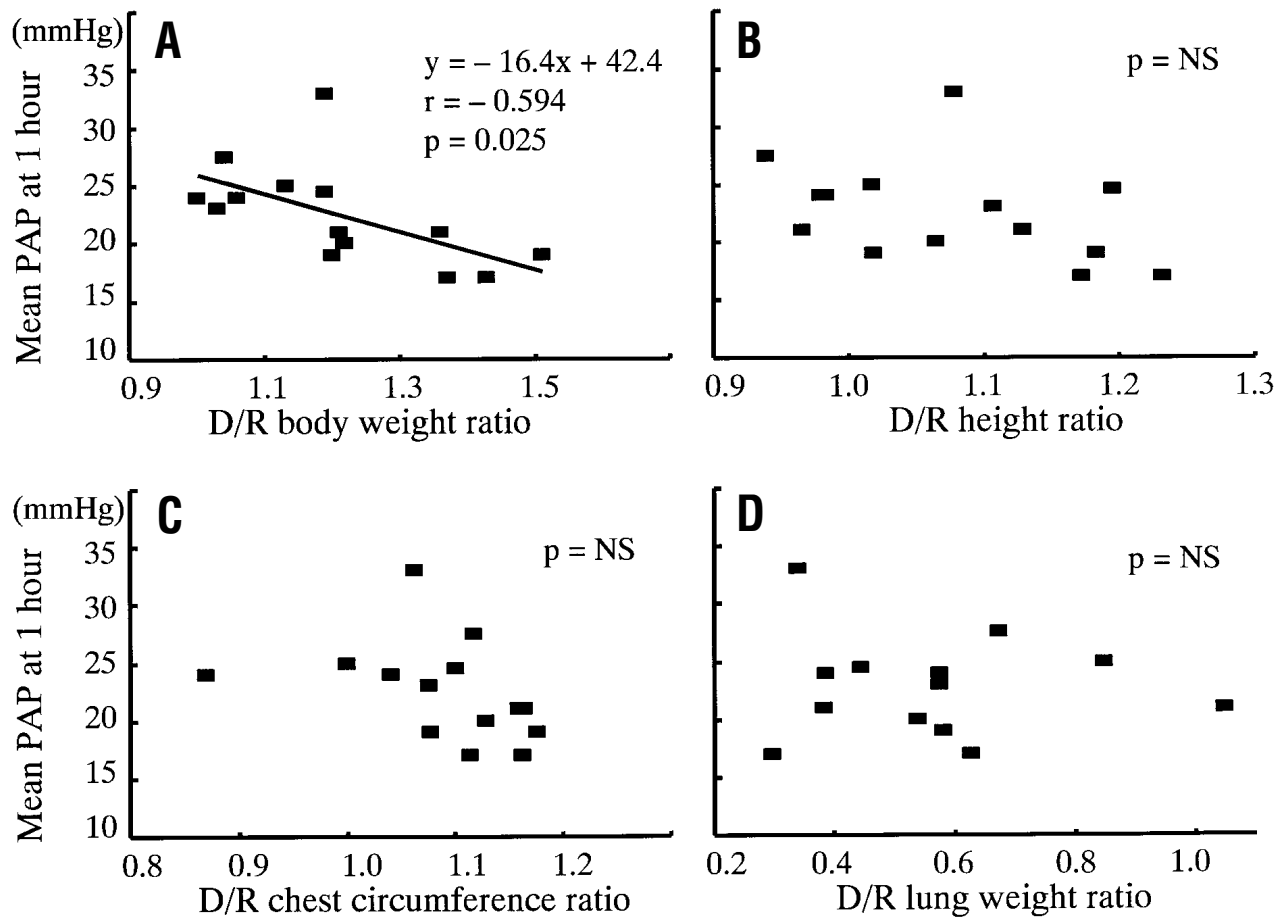

Figure 1. Relationship between size parameters and mean PAP at 1 hour after reperfusion: $A$, D/R body-weight ratio; $B, D / R$ height ratio; $C, D / R$ chest-circumference ratio; and $D, D / R$ lung-weight ratio. A significant negative correlation was present between $D / R$ body-weight ratio and mean PAP at 1 hour $(r=-0.594, P=.025)$.
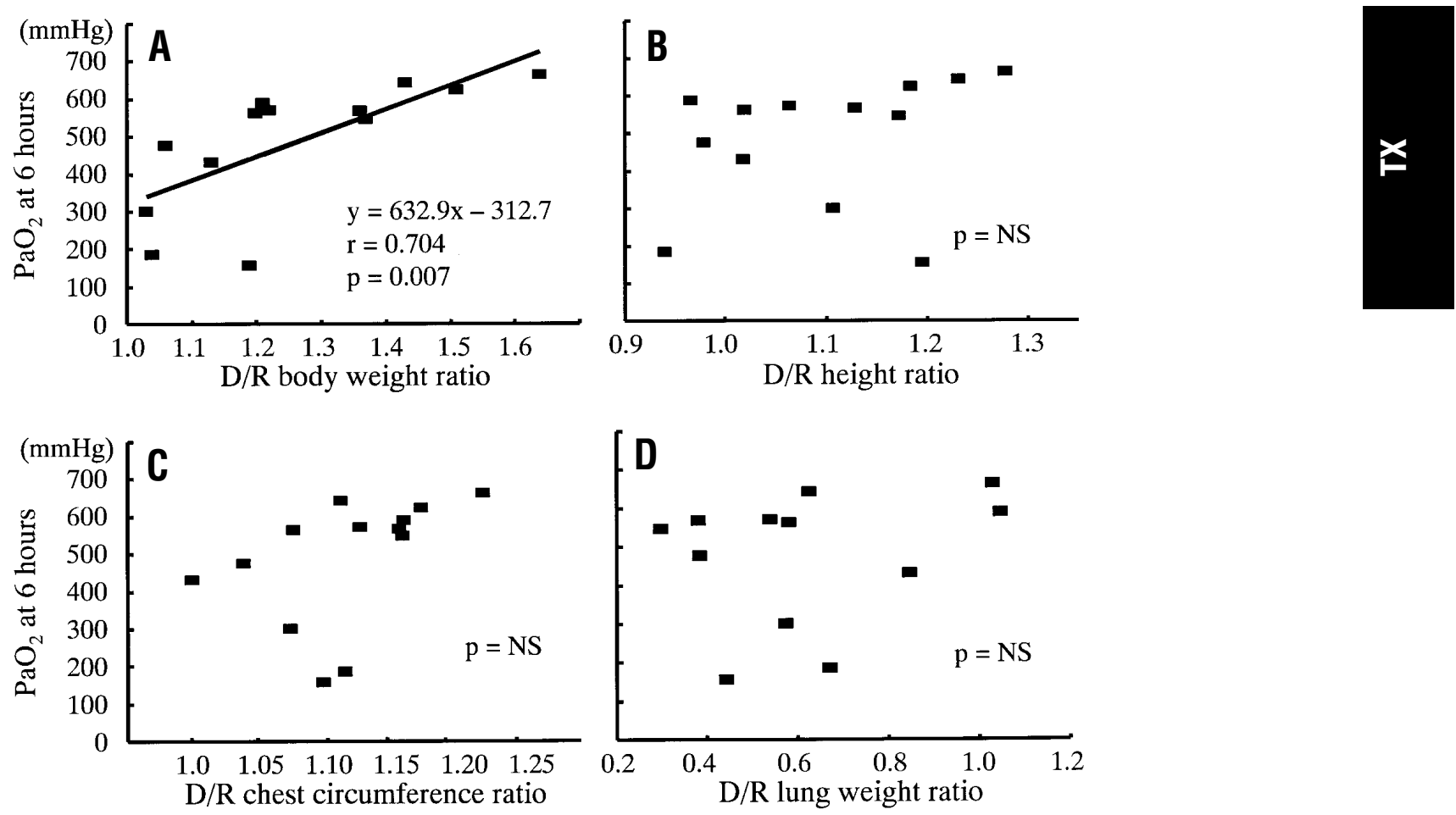

Figure 2. Relationship between size parameters and $\mathrm{PaO}_{2}$ at 6 hours after reperfusion: $A, D / R$ body-weight ratio; $B, D / R$ height ratio; C, D/R chest-circumference ratio; and $D, D / R$ lung-weight ratio. A significant correlation was present between $\mathrm{D} / \mathrm{R}$ body-weight ratio and $\mathrm{PaO}_{2}$ at 6 hours $(r=0.704, P=.007)$. 


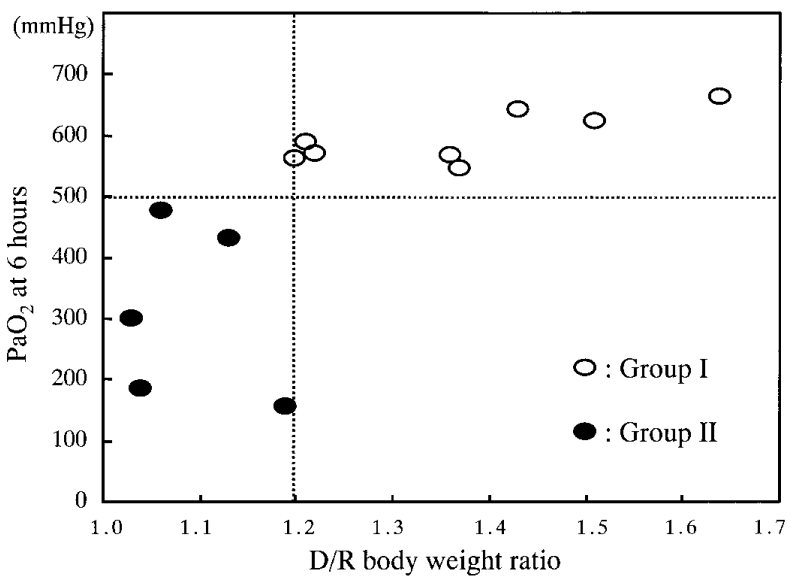

Figure 3. Relationship between $\mathrm{D} / \mathrm{R}$ body-weight ratio and $\mathrm{PaO}_{2}$ at 6 hours after reperfusion. All recipients with a $D / R$ body-weight ratio of 1.2 or greater had $\mathrm{PaO}_{2}$ exceeding $500 \mathrm{~mm} \mathrm{Hg}$, and they were classified in group 1 . In contrast, all recipients with $D / R$ body-weight ratio of less than 1.2 had $\mathrm{PaO}_{2}$ of less than $500 \mathrm{~mm} \mathrm{Hg}$ or died before 6 hours, and they were classified in group 2 .

\section{Materials and Methods}

Seventeen bilateral lobar lung allotransplant operations were performed in pairs of adult mongrel dogs. Body weight, height (the length from the manubrium to the ischial tuberosity), and chest circumference (the first submammary thoracic perimeter) were measured before examination.

\section{Donor Operation}

Seventeen adult mongrel dogs weighing between 10.5 and $19.8 \mathrm{~kg}$ were used. Donor dogs were premedicated with intramuscular injections of ketamine hydrochloride $(5 \mathrm{mg} / \mathrm{kg}$ ) and atropine sulfate $(0.03 \mathrm{mg} / \mathrm{kg})$ and anesthetized by means of an intravenous injection of thiopental sodium $(5 \mathrm{mg} / \mathrm{kg})$. They were intubated and placed on mechanical ventilation, with a tidal volume of $20 \mathrm{~mL} / \mathrm{kg}$, a respiratory rate of 20 breaths/min, and an inspirated oxygen fraction of 1.0. With the animals in the supine position, a median sternotomy was made. After the thymus was removed and the azygous vein was divided, both vena cavae, the aorta, and the trachea were isolated. Heparin sodium (400 IU/kg) was administered systemically. The trachea was stapled, leaving the lungs well inflated with $100 \%$ oxygen. A double lung block was excised without flushing and cooled in cold saline solution. Right lobar grafts (middle, lower, and cardiac lobes) were prepared by means of an upper lobectomy. Left lobar grafts (left lower lobe) were prepared by performing upper lobectomy and lingulectomy. Before implantation, grafts were weighed.

\section{Recipient Operation}

Seventeen adult mongrel dogs weighing between 9.8 and $14.4 \mathrm{~kg}$ were used. The recipient dogs were premedicated and anesthetized in the same manner as the donors. Each recipient was intubated and mechanically ventilated at 20 breaths/min and a positive end-expira-

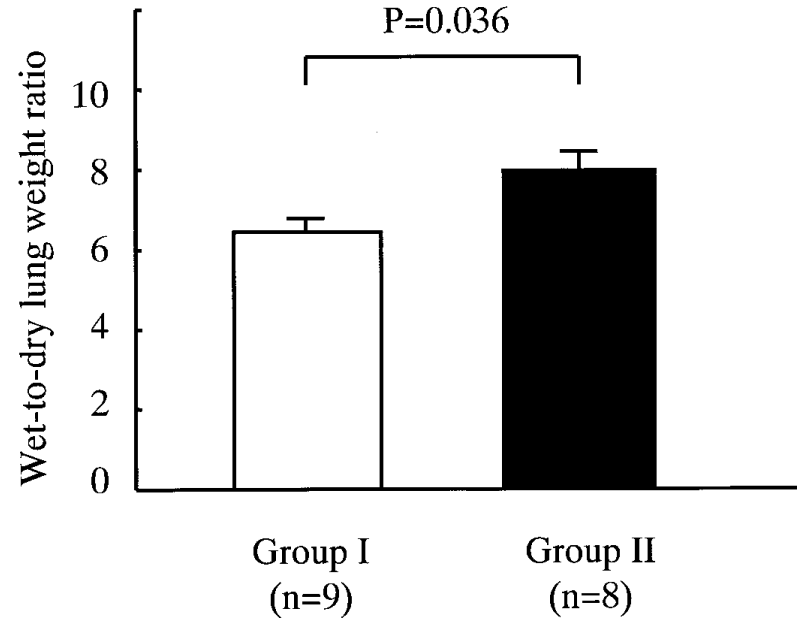

Figure 4. Wet/dry lung-weight ratio of transplanted lung after 6hour assessment period. It was significantly lower in group 1 (6.43 $\pm 0.35)$ than in group $2(7.97 \pm 0.59, P=.036)$.

tory pressure of $5 \mathrm{~cm} \mathrm{H}_{2} \mathrm{O}$. Anesthesia was maintained by means of a 50:50 mixture of nitrous oxide/oxygen and $0.5 \%$ to $1.0 \%$ halothane. A 5F Swan-Ganz catheter was placed in the main pulmonary artery through the right femoral vein to measure the pulmonary arterial pressure (PAP), the central venous pressure (CVP), and the cardiac output $(\mathrm{CO})$. A femoral arterial line was inserted for measuring the aortic pressure (AoP) and for the blood gas analysis. PAP, CVP, CO, and AoP were measured as baseline values, with the dogs in the supine position.

Then the animals were placed in the left decubitus position, and a right pneumonectomy was performed through a lateral thoracotomy in the right fifth intercostal space. The excised right lung was weighed. The right donor graft was brought into the chest cavity. The bronchus, the left atrium, and the pulmonary artery were anastomosed consecutively. Continuous over-and-over sutures were used for anastomoses. A chest tube was inserted and connected to negative suction $\left(-10 \mathrm{~cm} \mathrm{H}_{2} \mathrm{O}\right)$, and the right side of the chest was closed. Then the recipient dogs were turned from the left to the right decubitus position, and the left pneumonectomy and implantation of the left donor graft were performed. The excised left lung was weighed. Because cardiopulmonary bypass was not used in this study, the recipient was totally dependent on the transplanted right graft during the left graft implantation. Subsequently, a left atrial monitoring line was inserted to measure the left atrial pressure (LAP). A chest tube was inserted, and the left side of the chest was closed.

\section{Assessment of Pulmonary Function}

After transplantation, the recipient was placed in the supine position. Both lungs were ventilated with an inspired oxygen fraction of 1.0, and anesthesia was maintained with an intravenous infusion of thiopental sodium. The recipient dogs were observed for 6 hours after transplantation. AoP, PAP, CVP, and LAP were continuously recorded. $\mathrm{CO}$ and arterial and venous blood gases were measured every 1 hour. After the 6-hour assessment period, dogs were killed by means of intravenous administration of potassium chloride solution. 
TABLE 1. Assessment of lung and cardiac function of recipient

\begin{tabular}{|c|c|c|c|c|c|c|c|c|}
\hline \multirow{2}{*}{$\begin{array}{l}\text { Function } \\
\text { indicator }\end{array}$} & \multirow{2}{*}{$\begin{array}{c}\text { Before } \\
\text { transplantation }\end{array}$} & \multicolumn{6}{|c|}{ After transplantation } & \multirow{2}{*}{$\begin{array}{c}P \text { value } \\
\text { (group } 1 \text { vs group 2) }\end{array}$} \\
\hline & & $1 \mathrm{~h}$ & $2 \mathrm{~h}$ & $3 \mathbf{h}$ & $4 \mathrm{~h}$ & $5 \mathrm{~h}$ & $6 \mathrm{~h}$ & \\
\hline \multicolumn{9}{|c|}{$\mathrm{PaO}_{2}(\mathrm{~mm} \mathrm{Hg})$} \\
\hline Group 1 & $652.9 \pm 8.3$ & $604.2 \pm 19.1$ & $605.7 \pm 17.9$ & $592.6 \pm 12.3$ & $594.8 \pm 11.2$ & $584.6 \pm 13.4$ & $587.8 \pm 11.6$ & \\
\hline Group 2 & $655.5 \pm 18.2$ & $512.0 \pm 58.9$ & $437.8 \pm 84.8$ & $394.5 \pm 96.2$ & $376.2 \pm 89.7$ & $337.3 \pm 78.8$ & $309.1 \pm 64.0$ & .0085 \\
\hline \multicolumn{9}{|c|}{$\mathrm{PaCO}_{2}(\mathrm{~mm} \mathrm{Hg})$} \\
\hline Group 1 & $21.2 \pm 1.2$ & $25.7 \pm 2.0$ & $25.9 \pm 2.0$ & $27.0 \pm 3.1$ & $24.7 \pm 2.2$ & $25.0 \pm 2.6$ & $23.5 \pm 1.8$ & \\
\hline Group 2 & $22.9 \pm 1.1$ & $26.1 \pm 2.1$ & $26.6 \pm 1.8$ & $27.4 \pm 1.5$ & $27.9 \pm 1.6$ & $27.8 \pm 1.0$ & $30.2 \pm 2.0$ & .363 \\
\hline \multicolumn{9}{|c|}{ Mean AoP $(\mathrm{mm} \mathrm{Hg})$} \\
\hline Group 1 & $133.1 \pm 5.2$ & $87.6 \pm 10.5$ & $85.0 \pm 10.5$ & $86.8 \pm 10.9$ & $80.6 \pm 10.0$ & $79.8 \pm 10.2$ & $76.4 \pm 11.9$ & \\
\hline Group 2 & $122.6 \pm 5.2$ & $98.0 \pm 5.4$ & $95.8 \pm 9.6$ & $93.4 \pm 7.7$ & $96.4 \pm 12.0$ & $97.0 \pm 11.3$ & $83.6 \pm 12.9$ & .5451 \\
\hline \multicolumn{9}{|c|}{ Mean PAP $(\mathrm{mm} \mathrm{Hg})$} \\
\hline Group 1 & $20.6 \pm 1.9$ & $19.8 \pm 0.8$ & $18.6 \pm 1.0$ & $19.0 \pm 0.9$ & $19.0 \pm 0.8$ & $19.1 \pm 1.1$ & $19.3 \pm 1.1$ & \\
\hline Group 2 & $16.0 \pm 0.8$ & $24.6 \pm 0.8$ & $23.3 \pm 1.6$ & $22.7 \pm 1.5$ & $23.0 \pm 1.3$ & $23.2 \pm 1.6$ & $21.6 \pm 1.4$ & .0498 \\
\hline \multicolumn{9}{|c|}{ Mean CVP (mm Hg) } \\
\hline Group 1 & $6.7 \pm 0.6$ & $7.6 \pm 0.4$ & $7.6 \pm 0.5$ & $7.5 \pm 0.6$ & $7.1 \pm 0.5$ & $7.4 \pm 0.6$ & $7.3 \pm 0.7$ & \\
\hline Group 2 & $5.6 \pm 0.7$ & $7.4 \pm 1.3$ & $7.0 \pm 1.4$ & $6.8 \pm 1.2$ & $7.0 \pm 1.3$ & $6.7 \pm 1.1$ & $6.4 \pm 1.0$ & .5639 \\
\hline \multicolumn{9}{|c|}{ Mean LAP (mm Hg) } \\
\hline Group 1 & & $7.0 \pm 0.6$ & $7.0 \pm 0.6$ & $7.7 \pm 0.5$ & $7.9 \pm 0.5$ & $7.7 \pm 0.4$ & $8.1 \pm 0.6$ & \\
\hline Group 2 & & $7.6 \pm 0.8$ & $8.4 \pm 0.9$ & $7.7 \pm 1.0$ & $7.1 \pm 0.8$ & $7.2 \pm 0.6$ & $7.3 \pm 0.6$ & .865 \\
\hline \multicolumn{9}{|l|}{$\mathrm{CO}$ (L/min) } \\
\hline Group 1 & $2.30 \pm 0.22$ & $0.59 \pm 0.06$ & $0.60 \pm 0.06$ & $0.61 \pm 0.07$ & $0.62 \pm 0.08$ & $0.63 \pm 0.08$ & $0.59 \pm 0.08$ & \\
\hline Group 2 & $1.90 \pm 0.35$ & $0.70 \pm 0.06$ & $0.69 \pm 0.08$ & $0.63 \pm 0.05$ & $0.60 \pm 0.07$ & $0.60 \pm 0.07$ & $0.56 \pm 0.06$ & .7573 \\
\hline
\end{tabular}

All values are given as means \pm SEM

The transplanted lungs were excised to measure the wet/dry lungweight ratio, which was determined by the weight difference in the specimen before and after drying for 2 weeks at $90^{\circ} \mathrm{C}$.

\section{Animal Care}

All dogs received humane care in compliance with the "Principles of Laboratory Animal Care" formulated by the National Society for Medical Research and the "Guide for the Care and Use of Laboratory Animals" published by the National Institutes of Health (National Institutes of Health publication No.86-23, revised 1985).

\section{Statistics}

All values are given as means \pm SEM. The correlation coefficients between size parameters and postoperative pulmonary function were calculated with StatMate II software. One-way analysis of variance with repeated measures was used to determine whether an overall difference existed in lung function between the 2 groups during the 6hour assessment period.

\section{Results}

\section{Survival}

Thirteen of 17 recipients had successful transplantation and survived the 6-hour assessment period. Two died during left lung implantation, and 2 died at 105 and 110 minutes after reperfusion, respectively, as a result of severe lung edema.

\section{Size Disparity and Postoperative Pulmonary Function}

The donor/recipient (D/R) body-weight ratio ranged from 1.00 to 1.64 (average, 1.22). D/R height ratio ranged from 0.86 to 1.28 (average, 1.09). D/R chest-circumference ratio ranged from 0.86 to 1.23 (average, 1.09). $\mathrm{D} / \mathrm{R}$ lung-weight ratio ranged from 0.30 to 1.05 (average, 0.58 ). $\mathrm{D} / \mathrm{R}$ lung-weight ratio was defined as the ratio between the implanted graft and the recipient explanted whole lung.

The relationships among these 4 size parameters and mean PAP at 1 hour are depicted in Figure 1. One animal had high PAP because of filariasis and was excluded from the following hemodynamic analysis. A significant negative correlation was found between the D/R body-weight ratio and mean PAP at 1 hour $(r=-0.594, P=.025)$. There was no significant correlation among the other 3 size parameters and mean PAP at 1 hour.

The relationships between the 4 size parameters and $\mathrm{PaO}_{2}$ at 6 hours are depicted in Figure 2. A significant correlation was found between the D/R body-weight ratio and $\mathrm{PaO}_{2}$ at 6 hours $(r=0.704, P=.007)$. There was no significant correlation among the other 3 size parameters and $\mathrm{PaO}_{2}$ at 6 hours.

\section{Study Groups}

Because $\mathrm{D} / \mathrm{R}$ body-weight ratio correlated most with postoperative pulmonary function among the 4 size parameters, 
recipient animals were divided into the following 2 groups on the basis of D/R body-weight ratio: group $1(n=8), D / R$ body-weight ratio equal or greater than 1.2 (range, 1.201.64); group $2(\mathrm{n}=9), \mathrm{D} / \mathrm{R}$ body-weight ratio of less than 1.2 (range, 1.00-1.19).

All 8 recipients of group 1 survived the 6-hour assessment period, and their $\mathrm{PaO}_{2}$ values exceeded $500 \mathrm{~mm} \mathrm{Hg}$ at 6 hours, whereas only 5 of 9 recipients of group 2 survived for 6 hours, and their $\mathrm{PaO}_{2}$ values were less than $500 \mathrm{~mm} \mathrm{Hg}$ (Figure 3 ). The D/R body-weight ratio in the 4 animals that died before the 6-hour assessment period was 1.0, 1.02, 1.15, and 1.19 , respectively.

Excluding 2 animals in group 2 that died at 105 and 110 minutes after reperfusion, respectively, the results of gas exchange and hemodynamics of the surviving recipients during the 6-hour assessment period are shown in Table $1 . \mathrm{PaO}_{2}$ was significantly better in group 1 than in group $2(P=$ .0085). $\mathrm{PaCO}_{2}$ was not significantly different between the 2 groups. Mean AoP and CO were significantly decreased after transplantation $(P<.001)$ but were not significantly different between the 2 groups. Mean PAP was significantly lower in group 1 than in group $2(P=.049)$. Mean CVP and mean LAP were stable during the assessment period in both groups.

The wet/dry lung-weight ratio in group 1 was significantly lower than that in group $2(6.43 \pm 0.35$ vs $7.97 \pm 0.59, P=$ .036; Figure 4).

\section{Discussion}

Lung transplantation has become an established therapy for patients with a variety of end-stage lung diseases. Although the number of donors has remained relatively unchanged, the number of patients waiting for lung transplants has grown. ${ }^{1}$ In an effort to address the donor-shortage issue, living-donor lobar lung transplants have been performed with satisfactory intermediate survival and functional results. ${ }^{2,3}$ In this procedure 2 healthy donors are selected. One donor is selected for removal of the right lower lobe and the other for removal of the left lower lobe. These lobes are implanted to the recipient as the whole right and left lungs. Because a limited amount of lung tissue is transplanted, this type of operation is performed during cardiopulmonary bypass and seems to be best suited for children and small adults. However, the amount of tolerable size discrepancy between donors and recipients is currently unknown.

We used a canine bilateral living-donor lobar lung transplant model to evaluate the effect of donor-recipient size disparity on the early pulmonary function. A single donor was used in this experiment to simplify the model, whereas 2 healthy donors are required in the human setting. It is necessary to use a bilateral lung transplant model to assess the function of the relatively small transplanted grafts under physiologic conditions. In a single-lung transplant model, the native normal lung makes it difficult to evaluate the function of the transplanted graft under physiologic conditions. We avoided using cardiopulmonary bypass in this experiment to simplify the model itself and to exclude the adverse effect of cardiopulmonary bypass on the grafts. ${ }^{4}$ The recipient animal was totally dependent on the right transplanted graft during the left lower lobe implantation. For this reason, a relatively large graft (right middle, lower, and cardiac lobes) was used for the right side. In our study the weight of the right middle, lower, and cardiac lobes was about $40 \%$ of total donor lung weight, and that of the left lower lobe was about $25 \%$. Given the fact that the model has some difference from the human setting, we believe that this model is good enough to evaluate the effect of donor-recipient size disparity on the early pulmonary function.

Donor and recipient classically are size matched by means of measurement of the dimensions of the chest on radiograms. Several investigators have extensively studied lung size matching for single- and double-lung transplantation, as well as for heart-lung transplantation. Miyoshi and colleagues ${ }^{5}$ analyzed predicted vital capacity (VC) of donors and recipients in single- and double-lung transplantation. Massard and coworkers ${ }^{6}$ reported that the submammary thoracic perimeter appeared to be a satisfactory selection parameter in double-lung transplantation. Tamm and colleagues ${ }^{7}$ reported that size matching of donors and recipients in heart-lung transplantation could be achieved by comparing their predicted total lung capacity (TLC) values. Predicted values of VC and TLC are calculated from a knowledge of height, age, and sex. Egan and colleagues ${ }^{8}$ recommended listing recipients with an acceptable donor height range because lung size is not influenced by body weight.

Contrary to previous reports, the present study demonstrated the importance of $\mathrm{D} / \mathrm{R}$ body-weight ratio on early pulmonary function. Height, chest circumference, and lung weight did not predict the posttransplant PAP and $\mathrm{PaO}_{2}$ values. It is possible that canine chest differences to the primate may affect the interpretation of these results because body weight does not have a strong correlation to lung size in human subjects. However, the significant effect of $\mathrm{D} / \mathrm{R}$ body-weight ratio seen in the present experiment may have the following explanations. Although the effects of oversized grafts are better predicted by calculating VC or TLC, as proposed by Egan and colleagues, ${ }^{8}$ the effects of undersized grafts may be better predicted by $\mathrm{D} / \mathrm{R}$ bodyweight ratio because oxygen requirement of the recipient depends on body weight. When the transplanted grafts are small, underweight recipients may be better tolerated. Patients with cystic fibrosis are often malnourished yet have large chest cavities. Cohen and colleagues ${ }^{9}$ have reported excellent results in adult patients with cystic fibrosis who received lobes from donors with similar heights. We recently performed a bilateral living-donor lobar transplant for a 24-year-old woman with severe bronchiectasis using her sister's right lower lobe and her mother's left lower lobe. ${ }^{10}$ Although their heights were quite similar, there was a large weight discrepancy among them. 
From the results of early pulmonary function in group 2 (D/R body weight ratio, <1.2), it is evident that excessively small donor grafts cause the depression of $\mathrm{PaO}_{2}$ and elevation of PAP, resulting in acute lung edema, as manifested by the increased wet/dry lung-weight ratio. In contrast, excellent results obtained in group 1 (D/R body weight ratio, $\geq 1.2$ ) suggest that living-donor lobar lung transplant can be performed successfully with relatively small donor grafts, even without cardiopulmonary bypass. In fact, Bisson and colleagues have ${ }^{11}$ reported 2 successful cases of bilateral lobar transplant (right middle and lower lobe plus left lower lobe) from cadaveric donors performed without cardiopulmonary bypass.

We conclude that the $\mathrm{D} / \mathrm{R}$ weight ratio is an important predictor of early pulmonary function after living-donor lobar transplantation in this canine model in which the right middle, lower, and cardiac lobes were transplanted, along with the left lower lobe from a single donor.

We thank Tetsuo Kawakami for his expert technical assistance.

\section{References}

1. De Meester J, Smits JM, Persijn GG, Haverich A. Lung transplant waiting list: differential outcome of type of end-stage lung disease, one year after registration. J Heart Lung Transplant. 1999;18:563-71.

2. Starnes VA, Barr ML, Cohen RG, Hagen JA, Wells WJ, Horn MV, et al. Living-donor lobar lung transplantation experience: intermediate results. J Thorac Cardiovasc Surg. 1996;112:1284-90.

3. Starnes VA, Woo MS, MacLaughlin EF, Horn MV, Wong PC, Rowland $\mathrm{JM}$, et al. Comparison of outcomes between living donor and cadaveric lung transplantation in children. Ann Thorac Surg. 1999;68:2279-83.

4. Fullerton DA, McIntyre RC Jr, Mitchell MB, Campbell DN, Grover FL. Lung transplantation with cardiopulmonary bypass exaggerates pulmonary vasomotor dysfunction in the transplanted lung. J Thorac Cardiovasc Surg. 1995;109:212-6.

5. Miyoshi S, Schaefers HJ, Trulock EP, Yamazaki F, Schreinemakers H, Patterson GA, et al. Donor selection for single and double lung transplantation. Chest. 1990;98:308-13.

6. Massard G, Badier M, Guillot C, Reynaud M, Thomas P, Giudicelli R, et al. Lung size matching for double lung transplantation based on the submammary thoracic perimeter. J Thorac Cardiovasc Surg. 1993; 105:9-14.

7. Tamm M, Higenbottam TW, Dennis CM, Sharples LD, Wallwork J. Donor and recipient predicted lung volume and lung size after heartlung transplantation. Am J Respir Crit Care Med. 1994;150:403-7.

8. Egan TM, Thompson JT, Detterbeck FC, Lackner RP, Mill MR, Ogden WD, et al. Effect of size (mis)matching in clinical double-lung transplantation. Transplantation. 1995;59:707-13.

9. Cohen RG, Barr ML, Schenkel FA, DeMeester TR, Wells WJ, Starnes VA. Living-related donor lobectomy for bilateral lobar transplantation in patients with cystic fibrosis. Ann Thorac Surg. 1994;57:1423-8.

10. Date H, Yamamoto H, Yamashita M, Aoe M, Kubo K, Shimizu N. One year follow-up of the first bilateral living-donor lobar lung transplantation in Japan. Jpn J Thorac Cardiovasc Surg. 2000;48:648-51.

11. Bisson A, Bonnette P, El Kadi NB, Leroy M, Colchen A. Bilateral pulmonary lobe transplantation: left lower and right middle and lower lobes. Ann Thorac Surg. 1994;57:219-21. 